\title{
Does a course involving agricultural animals require a teaching protocol?
}

\begin{abstract}
$\mathrm{G}$ reat Eastern University, a PHS Assured and USDA registered institution, was facing a problem. For many years its IACUC had reviewed and approved a teaching protocol covering piglets and yearling sheep that were used to teach basic agricultural animal skills and procedures in the College of Agriculture. The protocol included animal restraint, hoof trimming, simple injections, piglet castration, and the like. Dr. Roger Gooding, a new faculty member, was to teach the course and he had no desire to fill out IACUC protocols and annual reports and have the IACUC approve any new techniques he wished to add to the course. Gooding had taught a similar course, without IACUC oversight, at the school from which he came, so he reviewed the Animal Welfare Act and its regulations (AWAR) and wrote to the IACUC that the definition of an animal under the AWAR excluded the sheep and pigs he was going to use because they are farm animals that would not be used for biomedical research ${ }^{1}$. The committee's rationale for its oversight requirement was based on the same definition, but with a different interpretation. The IACUC replied that the AWAR definition of an animal included any "warm-blooded animal, which is being used, or is intended for use for
\end{abstract}

research, teaching, testing, experimentation, or exhibition purposes, or as a pet. " Because there was no disagreement that Gooding's animals were to be used for teaching in a formal university course, the IACUC believed it was appropriate to require a teaching protocol. Of course, the committee was aware, as Gooding contended, that the word 'animal' excluded farm animals such as livestock intended for use as food or fiber or intended for use for improving animal nutrition, breeding, management, or production efficiency ${ }^{1}$. However, the IACUC had previously concluded that the teaching protocol had nothing to do with those topics and therefore the animals were not excluded from IACUC oversight. The IACUC's reply also included the AWAR statement that "where a school or department of a university or college uses or intends to use live animals for research, tests, experiments, or teaching, the university or college. . will be considered the research facility and will be required to register with the USDA. 2" That, claimed the IACUC, further supported the requirement for IACUC oversight. Gooding, as part of his reply to the committee, said that the section of the AWAR quoted by the IACUC only applied to animals used in research facilities, and his teaching had nothing to do with research or research facilities, and even when the animals he used would mature, they would be used for agricultural purposes only. The IACUC was becoming frustrated with Gooding's resistance and as a final statement, the committee also wrote that the College of Agriculture was the recipient of many USDA research grants, and even though Gooding's course was not directly funded by a grant, he was working in a research facility and an IACUC protocol was required.

What do you think? Does Gooding's course require an IACUC protocol? If you believe it does not legally require a protocol, do you think that the College of Agriculture's leadership should nevertheless require Gooding to submit a protocol?

\section{Jerald Silverman}

University of Massachusetts Medical School,

Worcester, MA, USA.

e-mail: Jerald.Silverman@umassmed.edu

Published online: 19 June 2019

https://doi.org/10.1038/s41684-019-0328-4
References
1. Animal Welfare Regulations Part 1 - Definition of Terms 7 U.S.C. 2131-2159; 7 CFR 2.22, 2.80, and 371.7.
2. Animal Welfare Regulations Part 2, Subsection C. $\$ 2.30$ Registration.

\section{Who decides when an agricultural species needs an animal use protocol?}

T his scenario introduces the debate regarding whether training individuals on basic management procedures with agricultural animals requires an approved IACUC protocol. While the Animal Welfare Act (AWA) does not cover this explicitly, Great Eastern University is a PHS assured institution. The key elements of the PHS assurance to consider pertaining to this scenario include: 1) which components of the institution are covered by the Assurance Letter; and 2) what is the institutional commitment to the AWA, the US Government Principles ${ }^{1}$, and the Guide for the Care and Use of Laboratory Animals ${ }^{2}$. Even though agricultural research is not typically funded by PHS, the PHS Assurance
Letter requires compliance with the regulations and guidelines listed above.

Unfortunately, the scope of the PHS assurance at Great Eastern University is unclear. It is possible that the College of Agriculture is not included in the Assurance Letter. In this case, it becomes important to evaluate the intended primary use of the animals - food animal production and management or biomedical teaching. USDA Animal Care Policy 17 states that "farm animals used for... the training of human or veterinary medical personnel in medical methods and procedures" would be regulated, while farm animals used for production purposes or agricultural teaching would be exempt from AWA coverage ${ }^{3}$.
Therefore, only the former would necessitate an IACUC protocol. In this case, the procedures appear to be agricultural training and thus would not require a protocol.

If the PHS Assurance Letter does cover all animals on campus, the entire program, including the use of agricultural animals, would be reviewable by the Office of Laboratory Animal Welfare (OLAW). The IACUC must then be committed to the AWA, the Guide for the Care and Use of Laboratory Animals ${ }^{2}$, and the US Government Principles ${ }^{1}$. The Guide defines a laboratory animal as "as any vertebrate animal (e.g., traditional laboratory animals, agricultural animals, wildlife, and aquatic species) produced for or used in research, 